\title{
RECUPERAÇÃO DE MANGUEZAIS: UM ESTUDO DE CASO NA BAIXADA SANTISTA DE SÃO PAULO, BRASIL
}

\author{
MENEZES, G.V. ${ }^{1}$; SCHAEFFER-NOVELLI, Y. ${ }^{2}$; POFFO, I.R.F. ${ }^{3} \&$ EYSINK, G.G.J. ${ }^{3}$ \\ ${ }^{1}$ Instituto Florestal, e-mail: giselamenezes@bol.com.br \\ ${ }^{2}$ Instituto Oceanogáfico, Universidade de São Paulo \\ ${ }^{3}$ CETESB - Companhia de Tecnologia e saneamento ambiental
}

\begin{abstract}
Menezes, G.V.; Shaeffer-Novelli, Y.; Poffo, I.R.F. \& Eysink, G.G.J. 2005. Mangrove recovering: a case study at Baixada Santista of São Paulo, Brazil. Braz. J. Aquat. Sci. Technol. 9(1):67-74. ISSN 1808-7035. We wanted to know about the possibility of mangrove recovery in Cubatão, Baixada Santista, São Paulo. We planted propagules and transplanted seedlings of Rhizophora mangle in three experiment stands in Cubatão. The results showed higher survival and development in two stands. After, we made preliminaries plantations with another specie of mangrove Laguncularia racemosa. Then, we and local fisherman community planted $R$. mangle in bigger stands. The results and conclusions of this job are important for contribute politics of development and preservation in Baixada Santista, São Paulo.
\end{abstract}

Keywords: Rhizophora mangle, recovery, mangroves, Cubatão, Baixada Santista.

\section{INTRODUÇÃO}

A Baixada Santista, litoral de São Paulo, é um bom exemplo das pressões antrópicas que os manguezais vêm sofrendo. Estudos realizados pela CETESB - Companhia de Tecnologia de Saneamento Ambiental, a partir da interpretação de imagens de satélite e fotografias aéreas mostram que apenas $40 \%$ dos manguezais dessa região encontram-se em bom estado de conservação. Dentre as áreas da Baixada Santista, a de Cubatão é a mais degradada, onde apenas $17 \%$ dos $29 \mathrm{Km}^{2}$ de manguezais originais encontram-se em estado saudável (Silva et al., 1991). Esses fatos tornaram indispensáveis e urgentes estudos sobre a recuperação de manguezais.

No Brasil, os primeiros trabalhos sobre recuperação de manguezais, ocorreram nos estados da Bahia, Rio de Janeiro e São Paulo (Oliveira, 1975; Oliveira \& Krau, 1976; Moscatelli \& Almeida, 1994; Moscatelli et al. 1994 e 1997; César, 1995; Orge, 1997; Menezes et al. 1998 e Abrahão, 1998).

Os trabalhos de Oliveira (1975) e Oliveira \& Krau (1976) são os primeiros a apresentar preocupações sobre recuperação de manguezais no Brasil, fazem parte de uma série de publicações sobre a Baía de Guanabara, que a exemplo de outros autores estrangeiros, recomendavam o plantio de árvores de mangue.

Moscatelli et al. (1994) relataram para o período de 1989 a 1992, o plantio de Laguncularia racemosa, Avicennia schaueriana e Rhizophora mangle, na Lagoa Rodrigo de Freitas (RJ). Moscatelli \& Almeida (1994) realizaram o plantio de propágulos de $R$. mangle em oito áreas na Praia da Chácara, Angra dos Reis (RJ). Moscatelli et al. (1997) relataram as principais técnicas de recuperação utilizadas nos locais do Rio de Janeiro onde os autores tiveram projetos de restauração bem como os custos de algumas dessas atividades.

César (1995) relata o trabalho do SOS Mangue de Maragojipe, Bahia, que possui um programa de Educação Ambiental na cidade voltado para a conservação, preservação e recuperação dos manguezais da região. Orge (1997) comparou fixação, altura, número de folhas, ramos laterais e outros parâmetros de propágulos de $R$. mangle plantados em áreas com e sem influência de atividades petroleiras, durante o período de fevereiro de 1994 a dezembro de 1995, na Baía de Todos os Santos, Bahia. Abrahão (1998) utilizou diferentes metodologias de plantio de espécies de mangue em uma área de aterro hidráulico na llha de Santa Catarina, iniciando seus experimentos em maio de 1997.

Os primeiros trabalhos sobre recuperação de manguezais no Brasil começaram a ser relatado no início dos anos 90 . Além de trabalhos técnicos existiram iniciativas ligadas à educação ambiental e conservação de manguezais que procuraram por meio da participação popular, principalmente com crianças, plantar espécies de mangue, contribuindo assim para a recuperação e conservação deste ecossistema.

O presente estudo iniciou-se com um trabalho de caráter técnico e acadêmico, visando testar a possibilidade de recuperação dos manguezais em Cubatão, aplicando diferentes técnicas de plantio. Durante sua 
realização, uma parcela da comunidade ribeirinha foi mobilizada a participar desta atividade e, posteriormente, participaram de uma segunda etapa do trabalho com o plantio de mais de 5.000 propágulos de mangue vermelho.

\section{Caracterização da área de estudo}

A Baixada Santista, incluindo o Estuário de Santos e os ecossistemas costeiros associados, localizase na porção central do litoral do Estado de São Paulo, na costa sudeste brasileira, entre as coordenadas

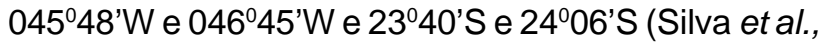
1991).

A área escolhida para os trabalhos foi o Município de Cubatão, Baixada Santista por ser, provavelmente, o mais alterado entre todos os estuários brasileiros. A alta degradação do meio ambiente, com o comprometimento dos manguezais, é resultado de uma série de impactos que atuam conjuntamente: efluentes domésticos e industriais, poluição do ar, dragagens, desmatamentos e modificação dos cursos originais dos rios, entre outros fatores. Áreas remanescentes de manguezal desprovidas de cobertura vegetal, além de constituírem alvo de invasões, reduzem drasticamente as funções deste importante ecossistema.

\section{MATERIAL E MÉTODOS}

Selecionou-se um local contíguo à cidade de Cubatão, desprovido de vegetação arbórea, com base em vistorias realizadas na região e na interpretação de fotos aéreas. Foram delimitadas 3 parcelas com reduzida regeneração natural de espécies de mangue e sedimento exposto nas marés mais baixas (Fig. 1). Para caracterização das áreas estudadas foram coletadas amostras de sedimento para análise granulométrica nas parcelas 1, 2 e 3 em 1993.

Optou-se por realizar experimento piloto com propágulos e plântulas de Rhizophora mangle, com base em observações do processo de regeneração natural da vegetação de mangue nas proximidades da área de estudo. Os propágulos foram coletados quando recém-caídos no substrato e em bom estado fitossanitário. As plântulas utilizadas apresentavam entre 0,3 a 0,5 m de altura, sem presença de ramificações ou rizóforos ("raízes-aéreas"), possuindo um par de folhas, no mínimo. Durante o experimento procurou-se: a) avaliar a capacidade do estabelecimento de Rhizophora mangle em sedimentos da região; b) testar a influência do estágio de desenvolvimento (propágulo ou plântula) sobre seu estabelecimento e crescimento; e, c) verificar a necessidade do emprego de fixadores artificiais para evitar uma eventual remoção das mudas pela maré.

Para tanto, foram estabelecidas três parcelas experimentais de plantio. As parcelas 1 e 2 localizamse em área fortemente degradada, apresentando sedimento exposto, sem vegetação remanescente. A parcela 3, localizada no interior de uma ampla clareira, em bosque com predomínio de R. mangle, apresenta substrato muito pouco consolidado. Nas proximidades, em um bosque de mangue a cerca de $100 \mathrm{~m}$ da parcela 3, foram demarcadas cerca de 50 plântulascontrole (não transplantadas) para avaliação do impacto produzido pelo transplante.

Para cada sítio experimental utilizou-se um total de 100 plântulas (50 com e 50 sem fixadores artificiais) e 50 propágulos, totalizando 3 tratamentos com universo amostral de 150 indivíduos. Cada parcela possuía duas fileiras com propágulos, duas fileiras com plântulas sem estaca e duas com estaca. O plantio foi realizado diretamente no sedimento, sem acréscimo de quaisquer corretivos ao substrato.

O experimento foi implantado no mês de maio de 1993 e monitorado até fevereiro de 1996. Por motivos técnicos que serão explicados posteriormente, plantaram-se novamente 100 plântulas (50 com e 50 sem estacas) ao lado da parcela 3, um ano após o início do experimento, obedecendo aos mesmos critérios de espaçamento.

No mês de março de 1995, foram coletados e plantados, tanto no campo quanto em vasos, propágulos de $L$. racemosa que se encontravam flutuando nas margens do Rio Capivari Grande próximo às parcelas 1 e 2. Em junho, quando possuíam em média $5,3 \mathrm{~cm}$ de altura e dois pares de folhas, os propágulos foram plantados em duas fileiras próximas a parcela 1 . 0 monitoramento foi realizado de fevereiro de 1996 a agosto de 1997.

Visando ampliar a área dos experimentos de recuperação e promover a participação popular em ações de recuperação, selecionou-se 4 áreas de manguezal degradado, com pouca regeneração natural, localizadas próximas às parcelas 1 e 2, que indicavam maior probabilidade de sucesso para um novo plantio. Optouse por utilizar popágulos de R. mangle

A participação popular se deu com a mobilização de crianças e adolescentes da Vila dos Pescadores, em Cubatão, que coletaram cerca de 5.800 propágulos de $R$. mangle, em aproximadamente duas semanas. Os propágulos foram armazenados em caixas de isopor e, periodicamente, imersos pelas crianças nas águas do Rio Casqueiro, de fronte à Vila dos Pescadores. No dia 19 de maio de 1995 houve a contagem e seleção dos propágulos, eliminando aqueles que se apresentavam quebrados, comidos (herbivoria) ou danificados de alguma forma. O plantio foi efetivado no dia seguinte, 
com maré vazante, em aproximadamente 2 horas. Após o plantio, cada área foi subdividida com a finalidade de facilitar o monitoramento.

\section{RESULTADOS}

Os resultados da análise granulométrica do sedimento superficial mostraram que a concentração da fração areias é de, respectivamente, $82,1 \% ; 54,2 \%$ e $14,2 \%$ nas parcelas 1, 2 e 3 (tabela 1).

A taxa de sobrevivência das plântulas de $R$. mangle foram altas e bastante parecidas nas parcelas 1 e 2 e muito pequenas nas parcelas 3 e 3B. A parcela
3B foi instalada ao lado da parcela 3, um ano após o início dos experimentos, com o objetivo de confirmar ou não os resultados obtidos na parcela 3. Observouse que a taxa de sobrevivência permaneceu constante após o primeiro ano do experimento (Fig. 2). A altura das plântulas mostrou-se similar nas três áreas de estudo e também com as plântulas-controle. Nas parcelas 3 e 3B, a altura obtida foi o resultado da média de muitos poucos indivíduos e, portanto, não pode ser considerada um valor representativo (Fig. 3). A produção de folhas foi bastante alta e próxima a 150 por indivíduo ao final de três anos nas plântulas das parcelas 1 e 2; próxima a 100 nas plântulas-controle e bastante baixa nos sobreviventes das parcelas 3 e 3B (Fig.

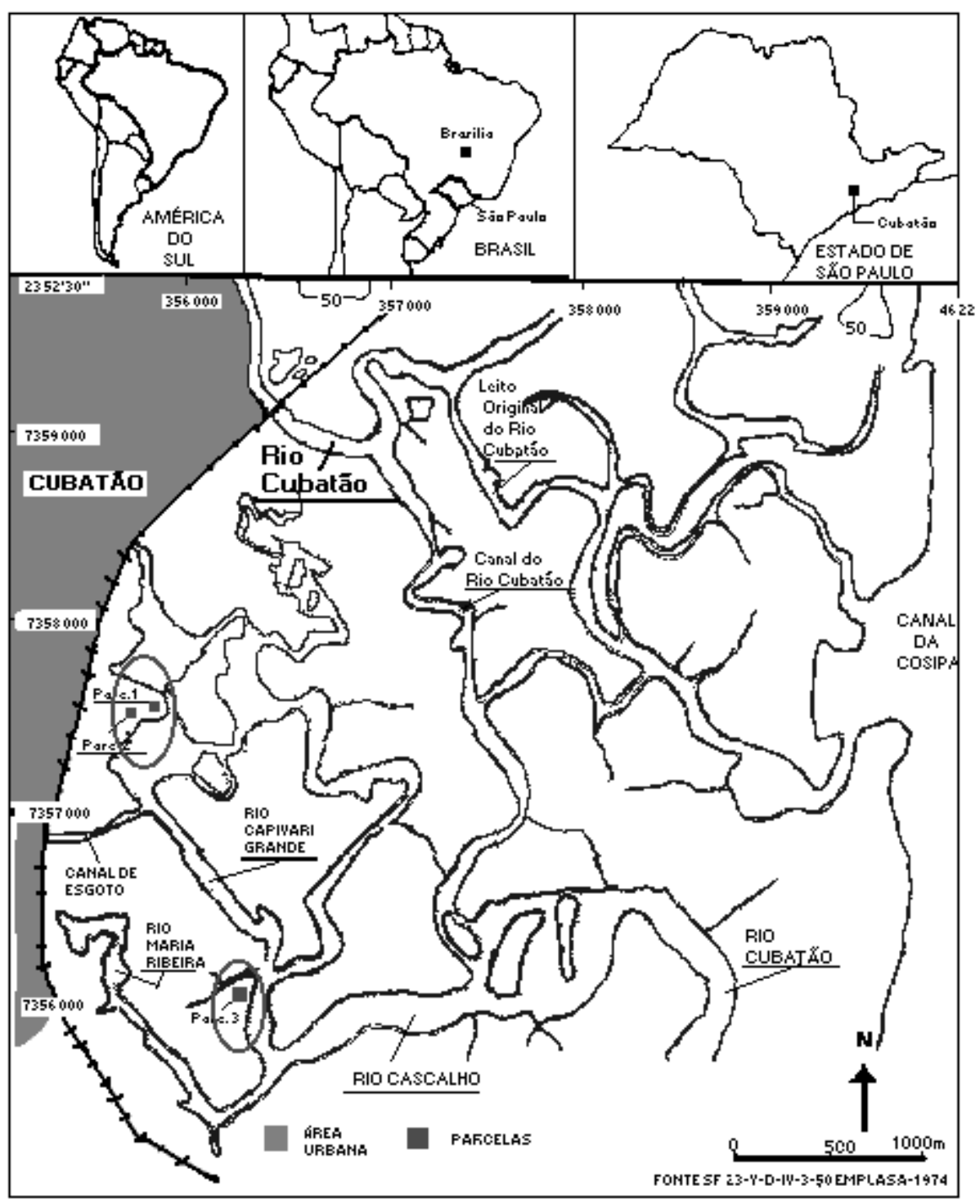

Figura 1 - Áreas de estudo delimitadas em verde (parcelas 1, 2 e 3) no estuário do Rio Cubatão. 
Tabela 1 - Análise granulométrica de amostras de sedimento superficial das parcelas 1,2 e 3 .

\begin{tabular}{lccc}
\hline \hline & $\begin{array}{c}\text { PARCELA 1 } \\
(\%)\end{array}$ & $\begin{array}{c}\text { PARCELA 2 } \\
(\%)\end{array}$ & $\begin{array}{c}\text { PARCELA 3 } \\
(\%)\end{array}$ \\
\hline AREIAS & 82,1 & 59,2 & 14,2 \\
SILTES & 15,8 & 25,7 & 45,7 \\
ARGILAS & 2,1 & 15,1 & 40,2 \\
\hline \hline
\end{tabular}

4). Esses dados mostram que as plântulas das parcelas 1 e 2 se desenvolveram mais, provavelmente por estarem em uma área aberta e receberem maior quantidade de sol.

Os valores da taxa de sobrevivência, produção de folhas e altura média apresentados pelos propágulos, mostraram-se similares às plantulas transplantadas. $A$ taxa de sobrevivência foi alta nas parcelas 1 e 2 , maior na dois do que na um, e próxima a zero na parcela 3 (figura 5, 6 e 7).

Com relação ao experimento com L. racemosa, as mudas transplantadas apresentaram taxa de sobrevivência igual a 86,4\% e altura média igual a $119,5 \mathrm{~cm}$ após 25 meses (figura 8). Os resultados das plântulas transplantadas com e sem estacas foram próximos como mostra a figura 9.

Os resultados obtidos com o plantio de propágulos pela comunidade não foram satisfatórios porque apresentaram baixíssima taxa de sobrevivência após três meses. No entanto, a experiência foi válida pois motivou a participação da comunidade, iniciando a sua conscientização ambiental sobre a preservação dos manguezais e serviu de ponto de partida para realização de novos trabalhos na região.

\section{DISCUSSÃO}

As plântulas transplantadas sofreram, no primeiro mês, uma pequena diminuição em altura que foi recuperada no segundo e terceiro mês após o transplante, provavelmente devido a um assentamento das plântulas no terreno. Isso também foi observado nos propágulos, porém de maneira menos acentuada.

As taxas de sobrevivência das plântulas, com e sem estaca, nas parcelas 1, 2 e 3 estiveram bastante próximas, o que permite inferir que a presença ou não de estacas nessa área não influiu na fixação e desenvolvimento das plântulas de $R$. mangle. Abraão (1998) comparando os resultados obtidos com o transplante de pequenas mudas de $A$. schaueriana com e sem proteção, encontrou valores de, respectivamente, 10 e $0 \%$, após 100 dias.

Os valores encontrados para as taxas de sobrevivência das plântulas e propágulos nas parcelas 1 e 2 foram superiores a $70 \%$ no decorrer do experimento, o que é considerado um valor alto pela literatura. A taxa

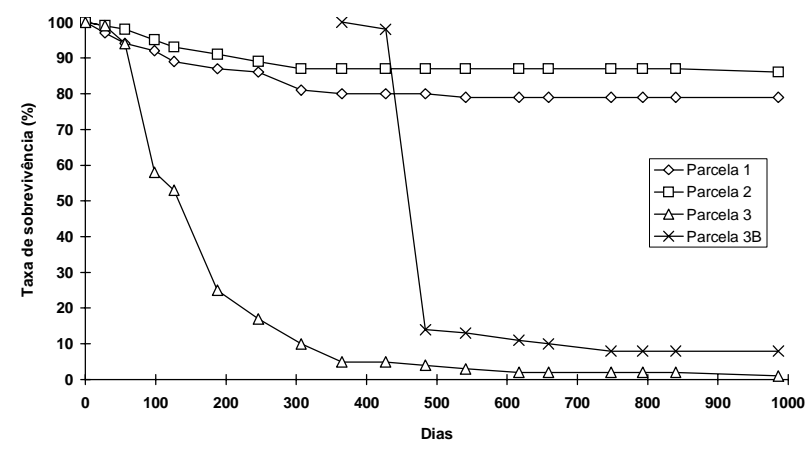

Figura 2 - Taxa de sobrevivência média para as plântulas de $R$. mangle nas parcelas 1, 2, 3 e 3B e plântulas-controle.

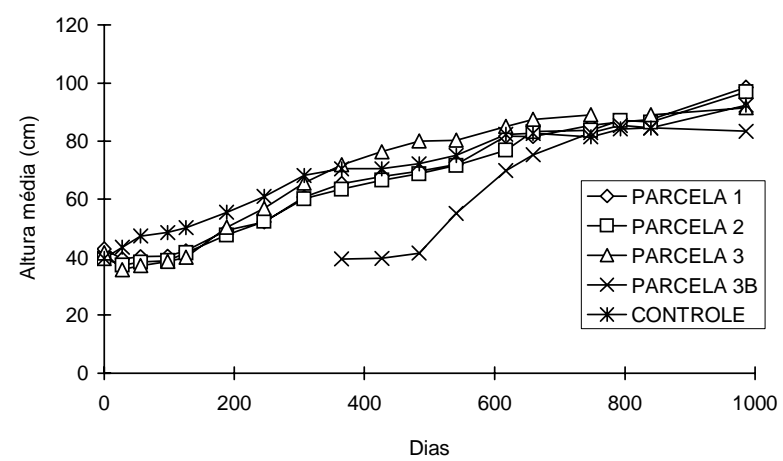

Figura 3 - Altura média $(\mathrm{cm})$ para as plântulas de $R$. mangle nas parcelas 1, 2, 3 e 3B e plântulas-controle.

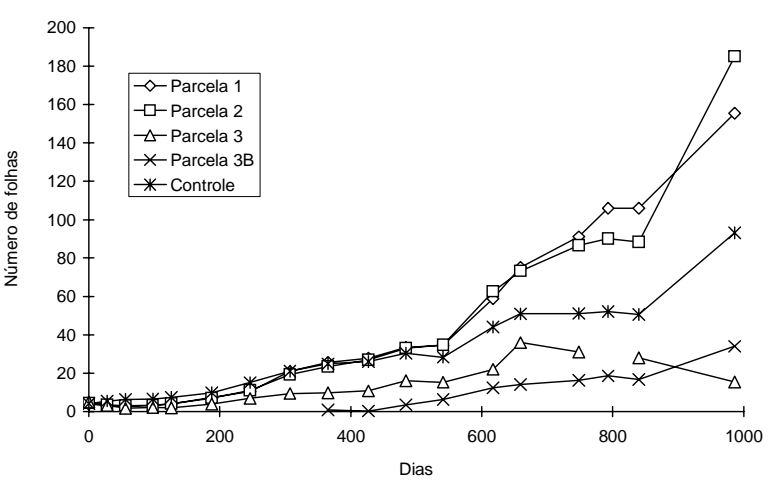

Figura 4 - Número médio de folhas para as plântulas de $R$. mangle nas parcelas 1, 2, 3 e 3B e plântulas-controle.

de sobrevivência encontrada para os propágulos na Flórida variou entre 14 a $86 \%$ e foi inversamente proporcional ao grau de exposição às ondas (Goforth \& Thomas, 1979), sendo que a sobrevivência encontrada para os propágulos em regiões abrigadas (71\%) foi similar àquela encontrada nas parcelas 1 e 2. Lewis III (1979) encontrou taxas de sobrevivência para propágulos plantados nas Ilhas Virgens, variando de 0 a 100\% dependendo do local, sendo que a média de sobrevivência foi igual a $75 \%$. Plantações de R. mangle com dife- 


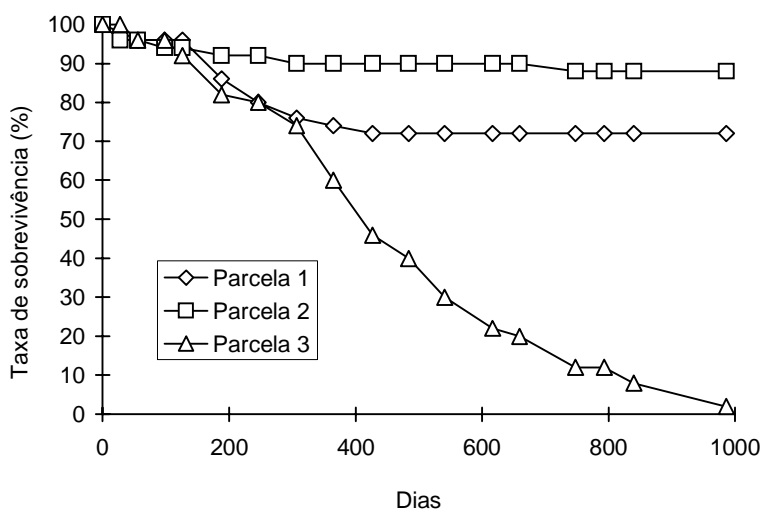

Figura 5 - Taxa de sobrevivência para os propágulos de $R$. mangle nas parcelas 1, 2 e 3 .

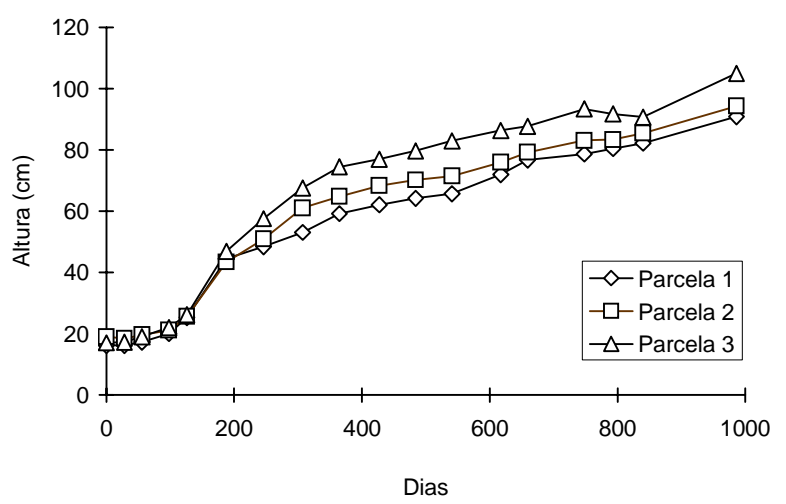

Figura 6 - Altura para os propágulos de $R$. mangle nas parcelas 1 , 2 e 3.

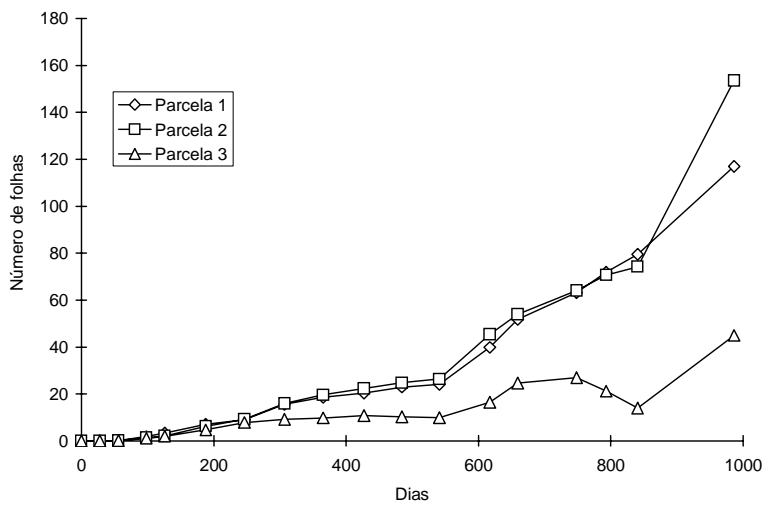

Figura 7 - Número de folhas para os propágulos de $R$. mangle nas parcelas 1,2 e 3.

rentes espaçamentos em Cuba, mostraram taxas de sobrevivência superiores a 85\% (Pádron, 1997).

No entanto, os valores obtidos na parcela 3 foram muito baixos, estando ao redor de 5 e $60 \%$ para as plântulas e propágulos após um ano de experimento; 2 e $20 \%$ após dois anos e $2 \%$ para ambos no final do monitoramento. $\mathrm{O}$ transplante das plântulas foi realiza-
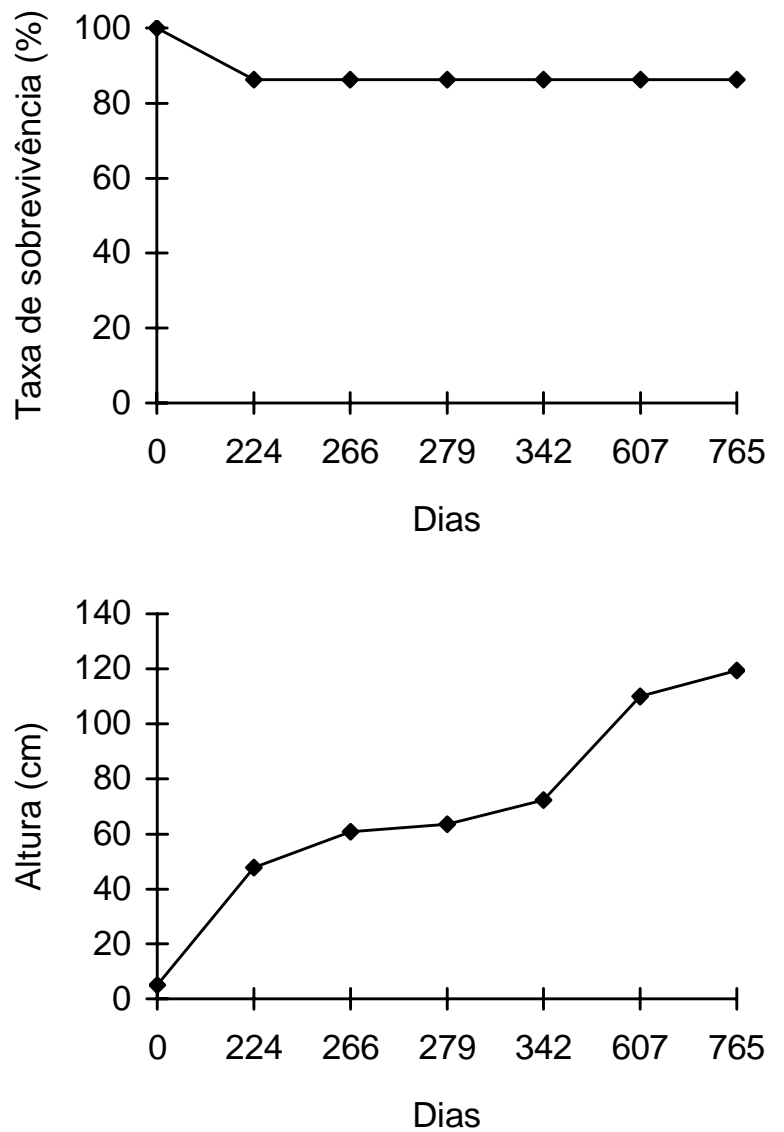

Figura 8 - Taxa de sobrevivência e altura dos indivíduos de $L$. racemosa transplantados.

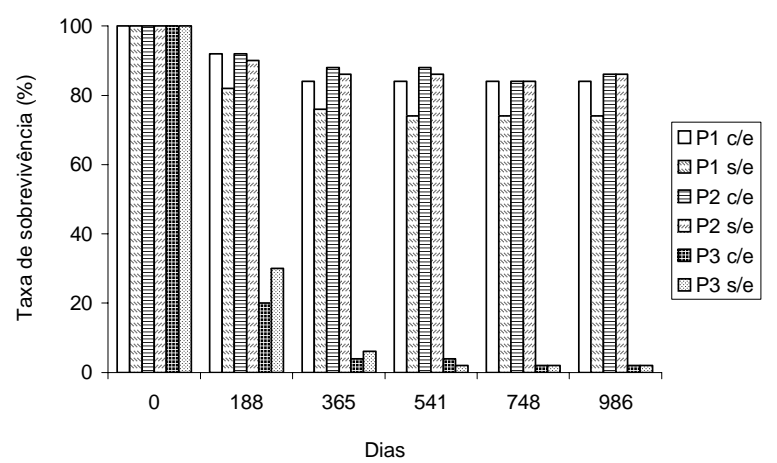

Figura 9 - Comparação das taxas de sobrevivência das plântulas com estaca (c/e) e sem estaca (s/e) nas parcelas 1,2 e 3 aos $188,365,541,748$ e 986 dias após o transplante.

do novamente em uma parcela denominada 3B, que se localizava ao lado da 3, no segundo ano do experimento, sendo que as taxas de sobrevivência encontradas foram igualmente muito baixas. 
Os resultados obtidos mostraram poucas diferenças entre o crescimento e taxa de sobrevivência das plântulas e propágulos nas parcelas 1 e 2. Assim como nesse estudo, Goforth \& Thomas (1979) encontraram valores próximos de sobrevivência entre as plântulas e os propágulos.

As plântulas transplantadas sofreram uma redução no número de folhas nos dois primeiros meses póstransplante. As parcelas 1 e 2 só atingiram o número inicial de folhas após o quarto mês do transplante e a parcela 3, entre o sexto e oitavo mês. Os propágulos começaram a liberar as primeiras folhas no segundo mês pós-plantio, sendo que no quarto mês os propágulos apresentavam um par de folhas ou mais, em média. Banus \& Kolemmainen (1975) registraram que os propágulos formavam o primeiro par de folhas entre 40 a 50 dias.

Como a redução do número de folhas só ocorreu nos indivíduos transplantados, infere-se que a diminuição ocorrida nas parcelas 1, 2 e 3 deve-se ao estresse sofrido pelo transplante. Hamilton \& Snedaker (1984) observaram que até 36 dias após o transplante, os indivíduos de $L$. racemosa e $R$. mangle perderam as foIhas.

As plântulas e propágulos da parcela 3 sempre tiveram um número médio de folhas bastante inferior ao dos outros grupos. Inicialmente, o número de folhas das plântulas-controle era superior ao das parcelas $1 \mathrm{e}$ 2 , sendo que esta diferença foi diminuindo no decorrer do primeiro ano do monitoramento. Após esse período, o número médio de folhas dos indivíduos das parcelas 1 e 2 aumentaram muito em relação ao controle sendo que no final do monitoramento (986 dias), os indivíduos das parcelas 1 e 2 possuíam 1,7 e 2,0 vezes mais foIhas que os do controle. Rabinowitz (1978) infere que a ausência de luz é um fator bastante crítico no crescimento e desenvolvimento das plântulas de Rhizophora mangle.

Jiménez \& Lugo (1985) dividiram o processo de desenvolvimento dos bosques em quatro fases: colonização, desenvolvimento, maturidade e senescência. A colonização depende do aporte, da taxa de enraizamento, da taxa de mortalidade dos propágulos e do grau de exposição dos bosques. Assim sendo, pode-se considerar que as parcelas 1, 2 e 3 enquadram-se na fase de colonização onde a chegada dos propágulos foi acelerada pelo homem e, que o bosque onde encontravam-se as plântulas-controle está pelo menos na segunda fase de desenvolvimento, quando a competição por espaço e luz é grande entre os indivíduos.

A fixação, sobrevivência e desenvolvimento dos indivíduos $R$. mangle nas parcelas 1 e 2 acabaram facilitando a fixação e desenvolvimento de outros propágulos, tanto de $R$. mangle como de outras espé- cies. Esse efeito também foi mencionado por Mac Nae, 1968 apud Lewis III (1982) e Lewis \& Dunstan (1975) apud Lewis III (1982) para outras espécies de mangue. Ao longo do experimento (32 meses), os parâmetros monitorados foram ligeiramente superiores na parcela 2 em comparação à parcela 1 , sendo que no final do monitoramento a taxa de sobrevivência das plântulas transplantadas e dos propágulos plantados foi, respectivamente, 7 e $16 \%$ superior na parcela 2 . As diferenças nos resultados indicam que o sedimento mais argiloso da parcela 2 pode ser mais adequado para 0 desenvolvimento e sobrevivência de $R$. mangle do que o sedimento mais arenoso da parcela 1.

Ressalta-se que para $L$. racemosa, o plantio direto dos propágulos no campo não se mostrou adequado, sendo que o plantio em vasos apresentou resultados melhores, com o posterior transplante das plântulas para o local desejado. Além disso, a utilização de $L$. racemosa em programas de revegetação seria bastante aconselhável pois o transplante de mudas apresentou altas taxas de sobrevivência e crescimento. Devese, no entanto, dar continuidade às pesquisas visando definir quais as condições ideais para o desenvolvimento dos propágulos, capazes de aumentar as taxas de sobrevivência.

Plantações de L. racemosa em Cuba com 15 anos apresentavam altura média igual a 8,7m (Pádron, 1997). Entre os 1.110 propágulos de L. racemosa plantados em vasos no Paquistão por Qureshi (1990) apenas $4 \%$ germinaram, enquanto que essas taxas foram superiores a $90 \%$ para as outras espécies utilizadas (Rhizophora mucronata, Avicennia marina, A. corniculatum, Ceriops tagal). Lewis \& Haines (1980) relatam que apenas 1 a 2\% dos 32 mil propágulos de Avicennia germinans plantados diretamente no sedimento de manguezais nas Ilhas Virgens sobreviveram.

Supõe-se que alguns fatores relacionados às condições impróprias dos propágulos entre o período da coleta e o plantio, tenham causado prejuízos vitais aos propágulos e estes acabaram morrendo após três meses do plantio. A literatura mostra que o plantio de $R$. mangle é realizado logo após a coleta dos propágulos, pois ao serem armazenados precisam de condições adequadas de armazenamento (Hamilton \& Snedaker, 1984). Qureshi (1990) armazenou os propágulos de Rhizophora mucronata, Ceriops tagale Avicennia marina por, no máximo, três dias antes de usá-los em plantações experimentais no Paquistão. McKee (1995) constatou que entre os propágulos de Rhizophora que morreram em bosques de Belize, $40 \%$ foi devido a dificuldades na fixação, $17 \%$ à predação, $17 \%$ à dessecação e $26 \%$ por causas desconhecidas.

Apesar dos resultados de sobrevivência dos propágulos plantados com a comunidade terem sido muito baixos, possivelmente pelo tempo de espera e 0 
armazenamento que sofreram, essa atividade foi importante porque conseguiu motivar alguns membros da comunidade a realizar outros plantios tanto espontâneamente como monitorados por biólogos e aumentar a compreensão sobre a importância dos manguezais na região. Soemodihardjo et al. (1997) salientam a importância do envolvimento dos habitantes locais nas atividades de restauração de manguezais, enquanto que Hong (1997), relata que a restauração de manguezais em Can Gio, Ho Chi Minh, foi feita principalmente por escolares. No Brasil, destaca-se a experiência de Maragojipe, Bahia, onde foram plantados mais de $50.000 \mathrm{~m}^{2}$ de manguezal pela comunidade durante atividades de educação ambiental (César, 1995).

\section{CONCLUSÕES}

a) Há possibilidade de recuperação dos manguezais degradados em Cubatão; b) a utilização ou não das estacas no caso das plântulas transplantadas não alterou os resultados nas áreas estudadas; c) as taxas de sobrevivência encontradas na parcela 2 (mais argilosa) foram um pouco maiores do que as da parcela 1 (mais arenosa), podendo indicar que o sedimento argiloso é mais adequado para a fixação e desenvolvimento de R. mangle; d) a elevada taxa de mortalidade na parcela 3 não foi devido à forma de plantio; e) o plantio direto dos propágulos de $L$. racemosa não é adequado, o melhor procedimento é um plantio intermediário em vasos ou sacos plásticos, com o posterior transplante das plântulas para o local desejado; f) os indivíduos de $L$. racemosa transplantados para o campo apresentaram maiores taxas de sobrevivência e maior incremento em altura do que os de $R$. mangle; $\mathrm{g}$ ) o envolvimento da comunidade em projetos de preservação e recuperação ambiental é viável e pode contribuir para o sucesso deste trabalho; e, h) quando os propágulos forem armazenados, deve-se tomar cuidados especiais na sua manutenção.

\section{AGRADECIMENTOS}

À CETESB - Companhia de Tecnologia de Saneamento Ambiental que possibilitou, estimulou e deu suporte quanto aos recursos financeiros e humanos necessários ao desenvolvimento desse trabalho. E, a todos os técnicos e amigos que participaram tanto do planejamento como das atividades de campo: Edmar Hatamura, Heronides P. da Silva, Jessé S. Alves, João W. S. Alves, Mara M. G. Lemos, Marisa Cury, Miguel Monteiro, Osvaldo A. da Silva, Roberto P. de Moraes, Sérgio Pompéia, Roney P. dos Santos.

\section{REFERÊNCIAS}

Abrahao, G. R. 1998. Técnicas para a implantação de espécies nativas de manguezal em aterro hidráulico visando a recomposição de ecossistemas costeiros (Via expresso Sul - Ilha de Santa Catarina Brasil). Dissertação de mestrado. Universidade Federal de Santa Catarina, Centro de Ciências Agrárias, $52 \mathrm{p}$.

Banus, M. D.\& Kolehmainen, S.E. 1975. Floating, rooting and growth of red mangrove (Rhizophora mangle L.) seedlings effects on expansion of mangroves in southwestern Puerto Rico. In: Walsh, G. E. ; S. C. Snedaker \& H. J. Teas, eds. Proceedings of the International Symposium on Biology and Management of Mangroves. Honolulu, Hawaii, October, 1974. v.1, p.370-384.

César, E. A. 1995. Lições tiradas da lama. Revista Nova Escola, ano 10, no87:44-46.

Goforth Jr., H.W. \& Thomas, J.R. 1979. Plantings of red mangrove (Rhizophora mangle L.) for stabilization of marl shorelines in the Florida Key. In: Cole, D. P., ed. Proceedings of conference on wetlands restoration and creation, 6, Flórida. Hillsborough Community College, 1979. p.207-230.

Hamilton, L.C. \& Snedaker, C.S. 1984. Handbook for mangrove area management. Environmental and Policy Institute East-West Center; International Union for the Conservation of Nature Resources; UNESCO. 123p.

Hong, P.N. 1997. Restauracion de ecosistemas de manglar en Vietnam. Estudio de caso del distrito de Can Gio, Ciudad Ho Chi Minh. In: Field, C., ed. $L$ a restauration de ecosistemas del manglar, OIMT \& ISME. p.81-104.

Jimenez, J.A. \& Lugo, A.E. 1985. Tree mortality in mangrove forests. Biotropica, 17(3): 177-185.

Lewis III, R.R., 1979. Large scale mangrove restoration on St. Croix, U.S.Virgin Islands. In: Cole, D. P., ed. Proceedings of conference on wetlands restoration and creation, 6, Flórida. Hillsborough Community College, 1979. p.231-242.

Lewis III, R.R. 1982. Mangrove forests. In: Lewis, R. R., ed. Creation and restoration of coastal plant communities. Flórida: CRC, 1982. p.153-171.

Lewis III, R.R. \& Haines, H.C. 1980. Large scale mangrove on St. Croix, U.S. Virgin Islands - II. Second year. In : COLE, D. P., ed. Proceedings of Conference on the Restoration and Creation of Wetlands, 7, Flórida. Hillsborough Community College, 1980. p.137-148.

Mckee, K.L. 1995. Seedlings recruitments patterns in a Belizean mangrove forest effects of establishmment ability and physico-chemical factors. Oecologia, 101:448-460. 
Menezes, G.V.; Poffo, I.R.F. \& Eysink, G.G.J. 1998. Estudo sobre a viabilidade e diferentes técnicas de recuperação de manguezais degradados em Cubatão, SP : Relatório Final. São Paulo. CETESB. 31p +2anexos.

Moscatelli, M. \&Almeida, J.R. 1994. Avaliação de crescimento e sobrevivência de Rhizophora mangle em restauração de manguezais no município de Angra dos Reis - RJ. In : I Simpósio Sul-Americano e II Simpósio Nacional de Recuperação de reas Degradadas, 1994, Foz do Iguaçu. Anais. Foz do Iguaçu, 1994. p.487-499.

Moscatelli, M.; De'Carli, C. \& Almeida, J.R. 1994. Avaliação preliminar do reflorestamento de manguezais, Lagoa Rodrigo de Freitas. In: Simpósio de Ecossistemas da Costa Brasileira: Subsídios a um Gerenciamento Ambiental, 3, 1993, Serra Negra, Anais. São Paulo : ACIESP, 1994. (1):131-34.

Moscatelli, M.; Teixeira, M.L.F. \& Almeida, J.R. 1997. O estado da arte na restauração de manguezais no estado do Rio de Janeiro. In: Simpósio Nacional de Recuperação de Áreas Degradadas, 3. Minas Gerais, 1997. Anais. p.525-534.

Oliveira, L.P.H. de, 1975. Recuperação biológica em manguezal na parte oeste da baía de Guanabara. II. Crescimento do manguezal na llha do Pinheiro. Mems Inst. Oswaldo Cruz, 51:503-521
Oliveira, L.P.H. de \& Krau, L. 1976. Estudos aplicados à recuperação biológica da Baia de Guanabara. Mems Inst. Oswaldo Cruz, 53:435-449.

Orge, M.D.R. 1997. Crescimento de Rhizophora mangle L. Em manguezais sob influência de atividades petroleiras na Baía de Todos os Santos. Dissertação de mestrado. Universidade Federal da Bahia, Instituto de Biologia. 96p.

Padrón, C.M. 1997. Restauracion de ecosistemas de manglar em Cuba: estudio de caso de Provincia Habana. In: Field, C., ed. La restauration de ecosistemas del manglar, OIMT \& ISME. p.176-186.

Qureshi, M.T. 1990. Experimental plantation for rehabilitation of mangrove forests in Pakistan. UNESCO. (Mangrove ecosystems occasional papers, n.4). 37p

Rabinowitz, D. 1978. Mortality and initial propagule size in mangrove seedlings in Panama. J. Ecol., 66:4551.

Silva, I.X.; de Moraes, R.P.; dos Santos, R.P.; Pompéia, S.L. \& Martins, S.E. 1991. Avaliação do estado de degradação dos ecossistemas da Baixada Santista - SP:relatório técnico. São Paulo, CETESB. 45p.

Soemodihardjo, S.; Wiroatmodjo, P.; Mulia, F. \& Harahap, M.K. 1997. In: Field, C., ed. La restauration de ecosistemas del manglar, OIMT \& ISME. p.105120. 